\title{
Límites del tratamiento de los datos personales en el ámbito laboral frente al uso de las tecnologías de la información y la comunicación en la era digital ${ }^{*}$
}

\author{
Lucero Galvis Cano, Ph. D.** \\ Daniel Alexander Pesca Mesa
}

Recibido: 8 de septiembre de 2019 • Aprobado: 19 de noviembre de 2019

\section{Resumen}

El siglo xxI se ha caracterizado por la digitalización y el uso de las tecnologías de la información y las comunicaciones en diversos escenarios de la vida socioeconómica, laboral, cultural, política e incluso recreativa del ser humano. Un sistema de interacción ius-informática sobresale en el ámbito laboral por la relación contractual basada en el análisis de los postulados teóricos de seguridad y confidencialidad de las TIC, tales como: "la globalización, la innovación tecnológica, la flexibilización y precarización del mercado de trabajo, el cambio institucional, las condiciones salariales, el papel de los sindicatos, la tendencia de la educación en la preparación

* El presente es producto del proyecto de investigación ius Digital gestionado en la Universidad Libre, Seccional Socorro, Santander - Colombia, Radicado N ${ }^{\circ}$ 2018-001.

Citar como: Galvis Cano, L. y Pesca Mesa, D. A. (2020). Límites del tratamiento de los datos personales en el ámbito laboral frente al uso de las tecnologías de la información y la comunicación en la era digital. Revista IUSTA, 52, 51-76. Dor: https://doi.org/10.15332/25005286.5482

** Abogada, Máster en Administración de Empresas, Especialista en Derecho administrativo, Especialista en Derecho penal, Ph. D. en Derecho. Docente investigadora y directora del Semillero de investigación Ius Digital - Proyecto Observatorio del Derecho de las nuevas tecnologías y seguridad digital, de la Universidad Libre de la Seccional Socorro Santander, Colombia. lucgalvis@hotmail.com. ORCID: 0000-0002-4305-8451.

**** Estudiante. Integrante del semillero de investigación IUs Digital de la Facultad de Derecho Universidad Libre, Socorro, Santander, Colombia. daniel.pesca1698@gmail.com. orcid: 00000003-1504-6995. 
de mano de obra, la migración, los derechos humanos y la equidad de género en la relación laboral" (Vega, 2015). El presente artículo hace una aproximación al análisis del alcance del derecho a las nuevas tecnologías en Colombia respecto al derecho a la protección de datos personales en el ámbito laboral; así como del equilibrio que se debe establecer en el ordenamiento jurídico, respecto al ejercicio del derecho a la intimidad, la información, la expresión, la libertad, la subordinación y las obligaciones que surgen de un sistema contractual interconectado por el mundo de la comunicación virtual (que evoluciona y se transforma a gran escala en diferentes dimensiones de la información y las comunicaciones). Los retos y avances jurídicos deben ser incorporados desde la teoría de los sistemas y el acoplamiento al mundo digitalizado, con el fin de garantizar los derechos de los diferentes actores que intervienen en la gestión integral de los datos personales en todos los estados.

Palabras clave: acoso cibernético, contrato laboral, derecho humano, digitalización, internet, intimidad, principios laborales, trabajo interactivo.

\title{
LIMITS OF THE PROCESSING OF PERSONAL DATA \\ IN THE WORKPLACE IN RELATION TO THE USE OF INFORMATION AND COMMUNICATION TECHNOLOGIES IN THE DIGITAL AGE
}

\begin{abstract}
The $21^{\text {st }}$ century has been characterized by the digitalization and use of information and communication technologies in various scenarios of the socio-economic, labor, cultural, political and even recreational life of the human being. A system of ius-informatics interaction stands out in the labor field for the contractual relationship based on the analysis of the theoretical postulates of ICT security and confidentiality, such as: "globalization, technological innovation, flexibilization and precariousness of the labor market, institutional change, wage conditions, the role of labor unions, the trend of education in the preparation of workforce, migration, human rights and gender equality in the labor relationship" (Vega, 2015). This article approaches the analysis of the scope of the right to new technologies in Colombia with respect to the right to the protection of personal data in the labor area; as well as the balance that must be established in the legal system, regarding the exercise of the right to privacy, information, expression, freedom, subordination and obligations arising from a contractual system interconnected by the world of virtual communication (which evolves and transforms on a large scale into different
\end{abstract}


dimensions of information and communications). The challenges and legal advances must be incorporated from the systems theory and the coupling into the digitalized world, in order to guarantee the rights of the different actors involved in the comprehensive management of personal data in all states.

Keywords: cyber bullying, labor contract, human right, digitalization, internet privacy, labor principles, interactive work.

\section{LiMITES DO TRATAMENTO DOS DADOS PESSOAIS NO ÂMBITO DO TRABALHO PERANTE O USO DAS TECNOLOGIAS DA INFORMAÇÃO E A COMUNICAÇÃO NA ERA DIGITAL}

\section{Resumo}

O século XXI tem se caracterizado pela digitalização e o uso das tecnologias da informação e as comunicações em diversos cenários da vida socioeconômica, trabalhista, cultural, política e inclusive recriativa do ser humano. Um sistema de interação ius-informática sobressai no âmbito do trabalho pela relação contrafatual baseada na análise dos postulados teóricos de segurança e confidencialidade das TIC, tais como: "a globalização, a inovação tecnológica, a flexibilização e precarização do mercado de trabalho, a mudança institucional, as condiciones salariais, o papel dos sindicatos, a tendência da educação na preparação de mão de obra, a migração, os direitos humanos e a equidade de gênero na relação trabalhista”(Vega,2015). Este artigo faz uma aproximação à análise do alcance do direito nas novas tecnologias na Colômbia respeito ao direito à proteção de dados pessoais no âmbito do trabalho; assim como do equilíbrio que se deve estabelecer no ordenamento jurídico, com respeito ao exercício do direito à intimidade, a informação, a expressão, a liberdade, a subordinação e as obrigações que surgem de um sistema contratual interconectado pelo mundo da comunicação virtual (que evolui e se transforma a grande escala em diferentes dimensões da informação e as comunicações) Os desafios e avanços jurídicos devem ser incorporados desde a teoria dos sistemas e o acoplamento ao mundo digitalizado com o objetivo de garantir os direitos dos diferentes atores que intervêm na gestão integral dos dados pessoais em todos os estados.

Palavras-chave: assédio cibernético, contrato de trabalho, direito humano, digitalização, internet intimidade, princípios trabalhistas, trabalho interativo. 


\section{Introducción}

En Colombia, la Constitución política de 1991 establece a la esfera de interpretación del derecho a la información personal, protegida en el artículo 15 y 20, el postulado general de: conocer, actualizar y rectificar cualquier información que exista sobre ellas, en bases de datos o archivos de entidades públicas o privadas (Remolina Angarita, 2013), así como la información de los usuarios, trabajadores de bancos, clínicas, hospitales, notarías, entre otros referentes que tratan información de carácter personal de terceras personas, los cuales están llamados a respetar los derechos y libertades de todo ser humano (Garzón, 2013).

El tratamiento jurídico acoge de forma particular los datos personales, por medio de la Estatutaria de protección de datos personales de carácter general (Ley 1581, 2012), la cual establece un marco jurídico basado en los principios de la dignidad humana, la confidencialidad, la calidad y la transparencia en todas las etapas de existencia del dato personal:

Esta ley tiene plena aplicación en el sector público y privado, e incide en el ámbito laboral, de manera que los empleadores, en su condición de responsables del tratamiento de los datos de sus empleados, deben observarla con ocasión de la recolección, almacenamiento, uso, circulación, etc. (Remolina Angarita, 2013)

En concordancia con la Constitución política, se estableció la exigencia, a las instituciones públicas o privadas, de controlar la gestión integral de datos al tratar información personal, como lo señala la Corte Constitucional al indicar que tienen el "deber constitucional de administrar correctamente y de proteger los archivos y bases de datos que contengan información personal o socialmente relevante" (Sentencia T-295, 2007).

Desde el año 2012 se instituye una serie de derechos, deberes y obligaciones para los titulares de la información personal (Barragán, 2016). De manera particular, en el ámbito laboral, aplica tanto para trabajadores como para empleadores que interactúan en un marco contractual cuyo objeto implica corresponsabilidad para la adecuada gestión y seguridad de la información y acoplamiento a los principios del sistema laboral y empresarial en la era de las Tecnologías de la Información y las Comunicaciones (TIC). 
Por lo tanto, es necesario preguntarse si existen los mecanismos jurídicos eficaces para proteger la información personal de los trabajadores, clientes internos y externos en general, frente al uso de las tecnologías de la información y las comunicaciones digitales en el ámbito empresarial. La respuesta involucra mecanismos de protección, relacionados con la interceptación de las comunicaciones, acceso abusivo, supresión de huellas, redireccionamiento sin control de información, privacidad por diseño y por defecto, políticas de privacidad y gestión integral de datos personales, rendición de cuentas, y responsabilidad en pro de la garantía de los derechos fundamentales de los trabajadores respecto a su información, entregada directa o indirectamente (desde el mismo momento en que se suscribe el contrato), que involucra su privacidad:

Tanto el derecho a la libertad de empresa (del empleador) como el derecho a la intimidad (del trabajador) tienen protección legal en el marco de una relación de trabajo. Como quiera que se trate de derechos fundamentales, dicha protección se halla en la fijación de límites entre el poder subordinante y la restricción de ciertos espacios de intimidad del trabajador. (Segura, 2005)

En este artículo, el autor presenta el alcance y los límites de la protección de datos personales en el ámbito laboral, atendiendo al uso de las nuevas Tic, y a la garantía de los derechos fundamentales que guardan relación directa e indirecta con el sistema iusinformático que caracterizan a cada caso en concreto. En el uso de medios de tecnología con fines personales, si no se respetan estándares mínimos para proteger la intimidad de los datos personales, por ejemplo al usar web cams o software rastreadores de información cuyo tratamiento no corresponde a los fines establecidos:

[...] se desarrollan mecanismos para conocer los aspectos más reservados de la conducta y vida del trabajador, monitorearlo en tiempo real a lo largo de su jornada laboral y, lo que más debe preocupar, ir almacenando información a lo largo de su vida laboral. (Raso, 2010, p. 34)

En su orden, como primera medida, el presente artículo describe las iniciativas internacionales en materia de protección de los datos personales de los trabajadores, que involucran los límites y recomendaciones según el actual Reglamento europeo, el análisis jurídico en general de la protección de datos personales, como 
un derecho independiente en Colombia, y su desarrollo en el derecho laboral, frente al uso de las Tic.

\section{Iniciativas y avances de regulación internacional de la protección de datos personales en el ámbito laboral}

La información personal que manejan las empresas tiene un valor representativo en los diferentes procesos administrativos, que se diferencian y no son excluyentes en el desarrollo del objeto social:

a. Con fines comerciales:

[...] para unas es el bien que comercializan en desarrollo de su objeto social principal, ofreciendo a terceros el suministro de la información que reposa en sus bases de datos. Para otras, se convierte en el insumo cardinal para fijar estrategias de publicidad, emprender tácticas de fidelización de los clientes, evaluar el riesgo crediticio de las personas, prestar servicios o vender bienes ajustados a la medida del perfil virtual de cada cliente, etc. (Remolina Angarita, 2013, p. 23)

b. Con fines de selección de personal:

"En el mundo laboral, los datos también son la fuente para realizar un proceso de selección de personas para proveer un cargo" (Remolina Angarita, 2013, p. 24).

c. Con el fin de cumplir obligaciones legales:

"Finalmente, los datos personales son información necesaria para cumplir obligaciones legales y que por tanto deben enviarse a las autoridades y terceros para fines de, entre otras, seguridad social, impuestos, investigaciones judiciales, etc.” (Remolina Angarita, 2013, p. 25).

d. Por último, con fines de control y seguimiento:

La vigilancia digital en las diferentes empresas involucra la caracterización de clientes internos y externos dentro de la organización. En virtud de la relación de subordinación, trabajadores de todos los niveles de dirección y ejecución laboral se exponen continuamente a ser controlados, sin tener delimitadas las políticas de acceso a la información personal o los programas de gestión integral de datos. 
Los datos personales identifican al titular, y así mismo su correlación crea un perfil sobre determinada persona en diferentes dimensiones:

[...] el nombre, domicilio, estado civil, conformación de su familia (nombre del cónyuge, hijos, etc.), historia clínica, formación académica, experiencia laboral, número telefónico, las fotos, los videos, el salario, la dirección de correo electrónico, las huellas dactilares, el comportamiento sexual, la pertenencia a grupos políticos, religiosos, sindicatos, el cumplimiento e incumplimiento de obligaciones dinerarias, los bienes, entre otros. (Remolina Angarita, 2013, p. 25)

A nivel internacional, la protección de datos personales ha tenido significativos avances normativos e iniciativas de regulación por parte de la OCDE, la OIT, con el tratado sobre "Protección de los datos personales de los trabajadores. Repertorio de recomendaciones prácticas” (1997), el Consejo de Europa y la Red Iberoamericana de Protección de Datos Personales.

En su orden, la OCDE (1980), de acuerdo a las directrices sobre "protección de la privacidad y flujos transfronterizos de datos personales", dice: "fueron adoptadas como una recomendación del Consejo de la ocDE apoyando los tres principios que aglutinan a los países de la OCDE: democracia pluralista, respeto de los derechos humanos y economías de mercado abiertas" (p. 2).

La orT da un paso importante en el desarrollo de los principios relacionados con la debida administración de los datos personales en los siguientes términos:

- El tratamiento de datos personales de los trabajadores debería efectuarse de manera ecuánime y lícita, y limitarse exclusivamente a asuntos directamente pertinentes a la relación de empleo del trabajador.

- En principio, los datos personales deberían utilizarse únicamente para el fin con el cual hayan sido acopiados.

- Los empleadores deberían evaluar periódicamente sus métodos de tratamiento de datos, con el objeto de: a) reducir lo más posible el tipo y el volumen de datos personales acopiados, y b) mejorar el modo de proteger la vida privada de los trabajadores.

- Las personas encargadas del tratamiento de datos personales deberían recibir periódicamente una formación que les permita comprender el proceso de acopio de datos y el papel que les corresponde en la aplicación de los principios. 
- El tratamiento de datos personales no debería conducir a una discriminación ilícita en materia de empleo u ocupación.

- Todas las personas, tales como los empleadores, los representantes de los trabajadores, las agencias de colocación y los trabajadores que tengan acceso a los datos personales de los trabajadores, deberían tener una obligación de confidencialidad, de acuerdo con la realización de sus tareas y el ejercicio de los principios de tratamiento de datos.

- Los empleadores deberían garantizar, mediante las salvaguardias de seguridad que permitan las circunstancias, la protección de los datos personales contra su pérdida y todo acceso, utilización, modificación o comunicación no autorizados.

- Los empleadores deberían verificar periódicamente que los datos personales conservados son exactos, actualizados y completos. (oIT, 1997, p. 33)

La comunidad europea reconoció la autonomía del derecho a la protección de datos personales, con la Carta de los Derechos Fundamentales, al establecer su tratamiento jurídico en el artículo 8 como: "un derecho fundamental, autónomo e independiente del derecho a la vida privada y familiar (art. 7o)" (Remolina Angarita, 2013, p. 26).

España fue uno de los primeros países que abanderó la protección de datos personales, incorporando el significado de dato personal en una sentencia del Tribunal Constitucional, en los siguientes términos:

[...] no se reduce solo a los datos íntimos de la persona "sino a cualquier tipo de dato personal, sea o no íntimo, cuyo conocimiento o empleo por terceros pueda afectar sus derechos, sean o no fundamentales, porque su objeto no es solo la intimidad individual, que para ello está la protección que el artículo 18.1 cE otorga, sino los datos de carácter personal". (sTc 292, 2000)

En América Latina, específicamente en Uruguay, se han emitido recomendaciones sobre el uso de redes y medios tecnológicos en el lugar de trabajo, y la protección de la privacidad de los datos personales. Aunque esto no es ajeno e independiente al derecho de subordinación del empleador sobre el trabajador, la jurisprudencia uruguaya hace énfasis sobre tres deberes que los trabajadores tienen para con su empleador en este sentido: 
- Innecesaridad de advertir a los trabajadores sobre el no uso de computadoras, porque el computador, al igual que las diferentes herramientas que se proveen al trabajador, son para uso de la empresa, no para el uso personal de los distintos operarios o empleados.

- El uso reiterado de las herramientas informáticas para fines particulares, en el centro de trabajo y en horario laboral, implica un incumplimiento grave y culpable del contrato de trabajo.

- El uso del ordenador, en cuanto que instrumento de trabajo inherente a la actividad y organización empresarial, debe ser tratado desde la perspectiva de la buena fe contractual debida a todo contratante. Si el trabajador utiliza el correo para asuntos personales, como por ejemplo para enviar chistes, mensajes religiosos, noticias, enlaces de Internet o cualquier otra actuación ajena a su trabajo, está utilizando para asuntos personales una mensajería laboral que no le pertenece, y ello determina una clara violación de los deberes de buena fe y lealtad propios de toda relación laboral. ${ }^{1}$ (Raso, 2013)

\section{Recomendaciones según el Reglamento europeo 679 (2016)}

El Reglamento europeo 679 del Parlamento Europeo y del Consejo (2016), en materia del tratamiento de datos personales en el ámbito laboral, establece, en el artículo 88:

1. Los Estados miembros podrán, a través de disposiciones legislativas o de convenios colectivos, establecer normas más específicas para garantizar la protección de los derechos y libertades en relación con el tratamiento de datos personales de los trabajadores en el ámbito laboral, en particular a efectos de contratación de personal, ejecución del contrato laboral, incluido el cumplimiento de las obligaciones establecidas por la ley o por el convenio colectivo, gestión, planificación y organización del trabajo, igualdad y diversidad en el lugar de trabajo, salud y seguridad en el trabajo, protección de los bienes de empleados o clientes, así como a efectos del ejercicio y disfrute, individual o colectivo, de los derechos y prestaciones

$1 \quad$ Véase las sentencias 312 y 103 del Tribunal Uruguayo de Apelaciones de Trabajo (2004, 2007). 
relacionados con el empleo y a efectos de la extinción de la relación laboral. (Reglamento europeo 679, 2016)

A la luz de la reglamentación europea, se requiere garantizar el principio de la dignidad humana en todos los ámbitos sociales en los cuales interactúan las personas, incluso el laboral:

[...] para preservar la dignidad humana de los interesados, así como sus intereses legítimos y sus derechos fundamentales, prestando especial atención a la transparencia del tratamiento, a la transferencia de los datos personales dentro de un grupo empresarial o de una unión de empresas dedicadas a una actividad económica conjunta, y a los sistemas de supervisión en el lugar de trabajo. (Reglamento europeo 679,2016 , art. 88)

Y dentro de los considerandos del Reglamento europeo, es importante destacar:

(71) El interesado debe tener derecho a no ser objeto de una decisión, que puede incluir una medida, que evalúe aspectos personales relativos a él, y que se base únicamente en el tratamiento automatizado y produzca efectos jurídicos en él o le afecte significativamente de modo similar, como la denegación automática de una solicitud de crédito en línea o los servicios de contratación en red en los que no medie intervención humana alguna. Este tipo de tratamiento incluye la elaboración de perfiles consistente en cualquier forma de tratamiento de los datos personales que evalúe aspectos personales relativos a una persona física, en particular para analizar o predecir aspectos relacionados con el rendimiento en el trabajo, la situación económica, la salud, las preferencias o intereses personales, la fiabilidad o el comportamiento, la situación o los movimientos del interesado, en la medida en que produzca efectos jurídicos en él o le afecte significativamente de modo similar. Sin embargo, se deben permitir las decisiones basadas en tal tratamiento, incluida la elaboración de perfiles, si lo autoriza expresamente el Derecho de la Unión o de los Estados miembros, aplicable al responsable del tratamiento, incluso con fines de control y prevención del fraude y la evasión fiscal, realizada de conformidad con las reglamentaciones, normas y recomendaciones de las instituciones de la Unión o de los órganos de supervisión nacionales y para garantizar la seguridad y la fiabilidad de un servicio prestado por el responsable del tratamiento, o necesario para la conclusión o ejecución de un contrato entre el interesado y un responsable del tratamiento, o en los casos en los que el interesado haya dado su consentimiento explícito. En cualquier 
caso, dicho tratamiento debe estar sujeto a las garantías apropiadas, entre las que se deben incluir la información específica al interesado y el derecho a obtener intervención humana, a expresar su punto de vista, a recibir una explicación de la decisión tomada después de tal evaluación y a impugnar la decisión. Tal medida no debe afectar a un menor." (Reglamento europeo 679, 2016, considerando 71, énfasis agregado)

En el marco de un contrato laboral, se establecen obligaciones, derechos y deberes, cuya protección y gestión de los riesgos, que surgen de la relación e interacción contractual, debe responder a estándares de seguridad y confidencialidad en materia del tratamiento de los datos, que surgen del cumplimiento de las funciones o labores desarrolladas en todos los niveles de ejecución, planificación y evaluación de la misión empresarial:

Los riesgos para los derechos y libertades de las personas físicas, de gravedad y probabilidad variables, pueden deberse al tratamiento de datos que pudieran provocar daños y perjuicios físicos, materiales o inmateriales, en particular en los casos en los que el tratamiento pueda dar lugar a problemas de discriminación, usurpación de identidad o fraude, pérdidas financieras, daño para la reputación, pérdida de confidencialidad de datos sujetos al secreto profesional, reversión no autorizada de la seudonimización o cualquier otro perjuicio económico o social significativo; en los casos en los que se prive a los interesados de sus derechos y libertades, o se les impida ejercer el control sobre sus datos personales; en los casos en los que los datos personales tratados revelen el origen étnico o racial, las opiniones políticas, la religión o creencias filosóficas, la militancia en sindicatos y el tratamiento de datos genéticos, datos relativos a la salud o datos sobre la vida sexual, o las condenas e infracciones penales o medidas de seguridad conexas; en los casos en los que se evalúen aspectos personales, en particular el análisis o la predicción de aspectos referidos al rendimiento en el trabajo, situación económica, salud, preferencias o intereses personales, fiabilidad o comportamiento, situación o movimientos, con el fin de crear o utilizar perfiles personales; en los casos en los que se traten datos personales de personas vulnerables, en particular niños; o en los casos en los que el tratamiento implique una gran cantidad de datos personales y afecte a un gran número de interesados” (Reglamento europeo 679, 2016) 
Si se hace referencia al tema particular del derecho a la intimidad y la navegación por internet, este no debe ser menoscabado por el abuso de poder del empleador con la utilización de medios desproporcionados, en aras de la necesidad de control de la actividad laboral y el seguimiento exhaustivo del trabajador por medios informáticos cada vez más sofisticados.

¿Por qué es importante el principio de proporcionalidad en este tema? Porque, así como lo señala el Tribunal Constitucional Español, el principio de proporcionalidad exige que el juez interprete y entienda el ámbito sobre el cual este límite externo se aplica, teniendo en cuenta no solo las vulneraciones de derechos fundamentales por poderes públicos, sino también la eficacia horizontal de los derechos fundamentales en el ámbito particular, como es el caso del derecho al trabajo (Forero, 2014). Otros mecanismos de intervención son posibles a través de técnicas de autorregulación, en un medio donde las nuevas tecnologías de la era digital cambian a pasos agigantados.

El referente valorativo de los medios utilizados por el empleador debe estar basado en el principio de proporcionalidad: la medida debe ser justificada, idónea, necesaria y equilibrada. Es decir, debe existir ponderación de derechos o bienes constitucionales con criterios más identificados por la legislación.

Un ejemplo del tema, como lo refiere Antoni Roig (2010), es "preferir controles indirectos sobre la navegación” (p. 23). Cuando un trabajador navega en internet de la empresa, por motivos personales que afectan su productividad, una sanción disciplinaria debería graduar su gravedad de acuerdo con la gravedad de la conducta, es decir, con criterios objetivos tales como duración, horario de trabajo, disminución de la productividad. Pero, si estamos frente a la comisión de un acto delictivo por parte del trabajador, será objeto de seguimiento en cuanto a los contenidos, por ejemplo, de los mensajes del correo electrónico de la empresa (Roig, 2010).

Con respecto a los medios audiovisuales de control, la instalación de circuitos de cámaras de televisión en ocasiones está plenamente justificada por su naturaleza, en muchos casos por razones de seguridad, productivos o como prevención de robos. En cuanto a los medios auditivos, la instalación de micrófonos que permiten interceptar escuchas y grabar conversaciones es difícilmente justificable por razones de seguridad en la empresa, lo cual apoya la afirmación de que suponen un atentado contra el derecho al secreto de comunicaciones de los trabajadores. (Saenz, 2015, p. 45) 


\section{La protección de datos personales como un derecho independiente en Colombia}

En cualquier Estado social de derecho debe reinar la justicia social, para que exista una verdadera construcción de paz. Tal justicia social se alcanza en la medida en que los Estados estén comprometidos en la implementación de mecanismos y herramientas propias de un "régimen de trabajo humano", con la prevalencia del principio de dignidad humana y de igualdad de oportunidades y garantías en el ejercicio de este.

Colombia es miembro de la oIT desde 1998, y ha venido desarrollando su normativa laboral en temas relacionados con "la libertad de asociación, la libertad sindical y el efectivo reconocimiento de asociación, la eliminación de todas las formas de trabajo forzoso u obligatorio, la eliminación de la discriminación en materia de empleo y ocupación y la abolición del trabajo infantil” (ort, 1997). Sin embargo, aún no se ha desarrollado el tema relacionado con la proporcionalidad en el derecho a la intimidad de los trabajadores, de acuerdo con las nuevas Tic.

De igual manera, se reconoce el derecho al trabajo con una visión global, como una oportunidad de satisfacer las necesidades de vida personal y profesional del trabajador, y como bienestar social de su familia. Esto en conformidad con el Pacto Internacional de Derechos Económicos, Sociales y Culturales, según lo siguiente:

Artículo 6.

1. Los estados partes en el presente Pacto reconocen el derecho a trabajar, que comprende el derecho de toda persona a tener la oportunidad de ganarse la vida mediante un trabajo libremente escogido o aceptado, y tomarán medidas adecuadas para garantizar este derecho.

2. Entre las medidas que habrá de adoptar cada uno de los estados partes en el presente Pacto para lograr la plena efectividad de este derecho, deberá figurar la orientación y formación técnico profesional, la preparación de programas, normas y técnicas encaminadas a conseguir un desarrollo económico, social y cultural constante y la ocupación plena y productiva, en condiciones que garanticen las libertades políticas y económicas fundamentales de la persona humana. (Ley 74, 1968, art. 6)

Artículo 11.

1. Los estados partes en el presente Pacto reconocen el derecho de toda persona a un nivel de vida adecuado para sí y su familia, incluso alimentación, vestido 
$\mathrm{y}$ vivienda adecuados, y a una mejora continua en las condiciones de existencia. Los estados partes tomarán medidas apropiadas para asegurar la efectividad de este derecho, reconociendo a este derecho la importancia esencial de la cooperación internacional fundada en el libre consentimiento. (Ley 74, 1968, art. 11)

$\mathrm{Y}$, respecto al derecho a la privacidad, establece:

Artículo 17.

1. Nadie será objeto de injerencias arbitrarias o ilegales en su vida privada, su familia, su domicilio o su correspondencia, ni de ataques ilegales a su honra y reputación. 2. Toda persona tiene derecho a la protección de la ley contra esas injerencias o esos ataques. (Ley 74, 1968, art. 17)

Así como la libertad de expresión:

Artículo 19.

1. Nadie podrá ser molestado a causa de sus opiniones.

2. Toda persona tiene derecho a la libertad de expresión; este derecho comprende la libertad de buscar, recibir y difundir informaciones e ideas de toda índole, sin consideración de fronteras, ya sea oralmente, por escrito o en forma impresa o artística, o por cualquier otro procedimiento de su elección. (Ley 74, 1968, art. 19)

En Colombia, el derecho a la protección de datos personales ha sido reconocido como un derecho autónomo e independiente en el contexto constitucional y laboral:

E1 derecho de la protección de datos personales no se reduce a los datos relacionados con la privacidad o intimidad de las personas. No debe confundirse el primero con el derecho a la intimidad. La protección de datos personales comprende cualquier naturaleza de información (privada, sensible, semiprivada y pública), lo cual implica que toda clase de dato personal del trabajador debe ser tratado debidamente por parte del empleador. (Remolina Angarita, 2013, p. 25)

La carta de principios de la comunidad europea sobre el manejo de datos personales incorpora su protección en el ámbito laboral (Ley 1581, 2012): "Dicho texto siguió de cerca la Recomendación R (89) 2 del Comité de Ministros del Consejo de Europa, sobre protección de los datos personales utilizados con fines de empleo" (Remolina Angarita, 2013, p. 26). 
Que no hubiera normatividad concreta, en materia de protección de datos personales, antes de la Ley Estatutaria 1581 de 2012 no quiere decir que no existieran normas que regularan el tema de la protección de datos a trabajadores por parte de los empleadores. Por lo que es importante el Código Sustantivo del Trabajo, que tiene dos reglas que guardaban conexión: como primera medida, se prohíbe al contratante "ejecutar o autorizar cualquier acto que vulnere o restrinja los derechos de los trabajadores o que ofenda su dignidad"; y como segunda medida, la anterior contravención es una norma de orden público, de modo que es de obligatorio cumplimiento que "los derechos y prerrogativas que ellas conceden son irrenunciables, salvo los casos expresamente exceptuados por la ley". Dicho de otra manera, dado que la protección de datos personales tiene el carácter de derecho autónomo y fundamental, regulado por la Constitución política en términos generales y condiciones de garantía y respeto (1991, art. 15), incluye el ámbito de las relaciones laborales. El empleador por ningún motivo está facultado para limitar el derecho a la privacidad de la información personal de los trabajadores, salvo en aquellos asuntos que expresamente se encuentren en la ley.

En Colombia la jurisprudencia ha sido la encargada de definir este aspecto. El babeas data fue primariamente concebido como una garantía del derecho a la intimidad, posteriormente se consideró como una manifestación de libre desarrollo de la personalidad y finalmente se catalogó como un derecho autónomo. (Remolina Angarita, 2013, p. 26)

Sobre este este último, la Corte Constitucional ha determinado que es [...] un derecho claramente diferenciado del derecho a la intimidad, cuyo núcleo esencial está integrado por el derecho a la autodeterminación informativa que implica, como lo reconoce el artículo 15 de la Carta Fundamental, la facultad que tienen todas las personas de conocer, actualizar y rectificar las informaciones que se hayan recogido sobre ellas en bancos de datos y en archivos de entidades públicas y privadas. (Sentencia T552, 1997)

La jurisprudencia colombiana se refiere, sobre la protección del historial laboral de un trabajador, acotando que allí se 
[...] encuentra registrada toda la información, positiva o negativa, relacionada con su hoja de vida, desempeño en el ejercicio de funciones tales como reconocimientos, llamados de atención, suspensiones. Así mismo, la historia laboral contiene la información referente al tiempo laborado, las cotizaciones a la seguridad social, los periodos de vacaciones disfrutados o pendientes, el registro de sus cesantías, nombramientos, ascensos, traslados, retiros, incapacidades, comisiones de trabajo, entre otros datos indispensables para el goce de las prestaciones laborales que nuestro ordenamiento concede al trabajador. (Sentencia T-718, 2005)

Por esto se hace hincapié en que el empleador es una gran base de datos, donde se consigna la información de todos sus trabajadores.

Por lo tanto, Colombia, con referencia al tratamiento jurídico de la protección de datos personales, requiere establecer en el ámbito laboral:

Tabla N.o 1

Derechos y libertades que se respetan en el tratamiento de datos personales en el ámbito laboral

\begin{tabular}{|c|c|}
\hline Derechos y libertades & Colombia \\
\hline $\begin{array}{l}\text { Contratación personal basada en los principios } \\
\text { de la protección de datos personales }\end{array}$ & $\begin{array}{l}\text { En proceso de implementar la política de pri- } \\
\text { vacidad y seguridad de la información personal, } \\
\text { "en particular en relación con las condiciones en } \\
\text { que los datos personales en el contexto laboral } \\
\text { pueden ser objeto de tratamiento sobre la base } \\
\text { del consentimiento del trabajador" }\end{array}$ \\
\hline $\begin{array}{l}\text { Ejecución del contrato laboral; incluidas las } \\
\text { obligaciones establecidas por la ley y los conve- } \\
\text { nios colectivos, estándares iberoamericanos de la } \\
\text { protección de datos personales, y Derechos ARco }\end{array}$ & - Protocolos de ejecución y seguimiento \\
\hline Modelo de gestión y seguridad digital & - Protocolos de gestión y riesgo \\
\hline Planificación y organización del trabajo & - Principio de planeación \\
\hline Igualdad y diversidad en el lugar de trabajo & $\begin{array}{l}\text { - En proceso de implementar la política de pri- } \\
\text { vacidad y seguridad de la información personal }\end{array}$ \\
\hline Salud y seguridad en el trabajo & $\begin{array}{l}\text { - En proceso de implementar la política de pri- } \\
\text { vacidad y seguridad de la información personal }\end{array}$ \\
\hline Protección de los bienes de empleados y clientes & $\begin{array}{l}\text { - En proceso de implementar la política de pri- } \\
\text { vacidad y seguridad de la información personal }\end{array}$ \\
\hline Prestaciones relacionadas con el empleo & - Protocolo de gestión del riesgo \\
\hline
\end{tabular}

Fuente: elaboración propia 
Es importante señalar que la protección reforzada, que establece la Constitución política de Colombia en los artículos 25 y 53 (los principios aplicables en materia laboral), enfatiza su aplicabilidad en toda relación de trabajo dentro del marco de la dignidad humana:

\section{Tabla N.o 2}

Principios mínimos fundamentales de protección en el derecho laboral

\begin{tabular}{|l|l|}
\hline \multicolumn{1}{|c|}{ En general } & \multicolumn{1}{|c|}{ En el Estatuto Laboral: } \\
\hline Igualdad de oportunidades para los trabajadores & $\begin{array}{l}\text { "Derecho al trabajo: Toda persona tiene derecho } \\
\text { al trabajo y goza de libertad para escoger profesión } \\
\text { u oficio, dentro de las normas prescritas en la } \\
\text { Constitución y en la ley" (Código Sustantivo del } \\
\text { Trabajo, art. 11) }\end{array}$ \\
\hline $\begin{array}{l}\text { Remuneración mínima vital y móvil, proporcio- } \\
\text { nal a la cantidad y calidad de trabajo }\end{array}$ & $\begin{array}{l}\text { Autonomía de la voluntad: El derecho al tra- } \\
\text { bajo se limita por el orden público, las buenas } \\
\text { costumbres, el mantenimiento del bien común } \\
\text { y el interés social }\end{array}$ \\
\hline Estabilidad en el empleo & $\begin{array}{l}\text { Obligatoriedad: "El trabajo socialmente es obli- } \\
\text { gatorio" (Código Sustantivo del Trabajo, art. 7) }\end{array}$ \\
\hline $\begin{array}{l}\text { "Irrenunciabilidad a los beneficios mínimos } \\
\text { establecidos en normas laborales" (Sentencia } \\
\text { T-149/95, 1995) }\end{array}$ & $\begin{array}{l}\text { Libertad de trabajo: Ejercicio libre y espontáneo } \\
\text { (excepto por orden de autoridad competente } \\
\text { (Código Sustantivo del Trabajo, art. 8) }\end{array}$ \\
\hline $\begin{array}{l}\text { "Facultades para transigir y conciliar sobre } \\
\text { derechos inciertos y discutibles" (Remolina } \\
\text { Angarita, 2013) }\end{array}$ & $\begin{array}{l}\text { Protección al trabajo: El estado protege el dere- } \\
\text { cho al trabajo en condiciones dignas, equitativas } \\
\text { justas frente a la desigualdad material y formal } \\
\text { entre trabajador y empleador. (Código Sustantivo } \\
\text { del Trabajo, art. 9) }\end{array}$ \\
\hline $\begin{array}{l}\text { "Situación más favorable al trabajador en caso } \\
\text { de duda en la aplicación e interpretación de } \\
\text { las fuentes formales del derecho" (Sentencia } \\
\text { T-800/99, 1999) }\end{array}$ & Protección al trabajo \\
\hline $\begin{array}{l}\text { "Primacía de la realidad sobre formalidades esta- } \\
\text { blecidas por los sujetos de las relaciones laborales" } \\
\text { (Sentencia T-800/99, 1999) }\end{array}$ & Protección al trabajo \\
\hline $\begin{array}{l}\text { "Garantía a la seguridad social, la capacitación, } \\
\text { el adiestramiento y el descanso necesario" (Sen- } \\
\text { tencia T-800/99, 1999) }\end{array}$ & Protección al trabajo \\
\hline $\begin{array}{l}\text { "Protección especial a la mujer, a la materni- } \\
\text { T-800/99, 1999) }\end{array}$ & Protección al trabajo \\
\hline
\end{tabular}

Fuente: elaboración propia 
Para el objeto de estudio, dentro del análisis de los principios laborales, regulado por el estatuto laboral colombiano, se visualiza un mayor desarrollo normativo del principio de la protección al trabajo, de acuerdo con el mejoramiento de las condiciones de dignidad, equidad y justicia, que requiere una relación contractual armónica.

Sin embargo, por razones de implementación de novedosas Tic, los principios de autonomía de la voluntad, la libertad de trabajo y, a su vez, el principio de protección al trabajo, se han visto desconocidos con ocasión de la desigualdad material y formal entre trabajador y empleador.

Ahora bien, la Corte Constitucional señala la importancia de que "los convenios internacionales del trabajo debidamente ratificados por Colombia hacen parte de la legislación interna" (Sentencia C-401, 2005). Por lo tanto: "La ley, los contratos, los acuerdos y convenios de trabajo, no pueden menoscabar la libertad, la dignidad humana ni los derechos de los trabajadores" (Const. 1991). Esto significa que el desarrollo del trabajo, como fin, principio y derecho, debe ser protegido por el Estado colombiano, dentro de los estándares de protección internacional, que singularizan la dignidad y libertad como principio y derecho fundantes.

\section{El desarrollo del trabajo en condiciones dignas y justas}

En el artículo 25 de la Constitución política se hace referencia al principio de dignidad en el trabajo "digno y justo", y la Corte Constitucional desarrolla dicho marco de protección del derecho al trabajo en la Sentencia T-124 de 1993 en la cual se precisa:

La dignidad (artículo 1 Constitución política) es un artículo de la persona y, en cuanto tal, todos tienen derecho a que sean tratados conforme a esa dimensión específicamente humana. Como bien lo ha afirmado la Corte, más que derecho en sí mismo, la dignidad es el presupuesto esencial de la consagración y efectividad del entero sistema de derechos y garantías contempladas en la Constitución.

La dignidad es un derecho fundamental, inherente a la calidad del ser humano, que no se puede relativizar y que conlleva el desarrollo de su naturaleza, razón por la cual es un presupuesto de la existencia de los demás derechos.

Tal como lo establece la Sentencia C-107 de 2002: 
Este derecho comporta la exigencia de su ejercicio en condiciones dignas y justas, es decir, su realización en un entorno sin características humillantes o degradantes, o que desconozca los principios mínimos fundamentales establecidos por la Constitución, y además que permita su desarrollo en condiciones equitativas para el trabajador.

El radio de protección del derecho al trabajo se ha ampliado de forma progresiva y garantista, en aras de facilitar al trabajador y empleador el cumplimiento del libre desarrollo de la personalidad y su realización como ser social que está evolucionando en un entorno digital. Por esto el presente estudio, a continuación, analiza el marco reglamentario europeo y colombiano sobre el tratamiento de datos personales, en particular en el ámbito laboral.

En la Sentencia T-768 de 2008, la Corte Constitucional resuelve un caso muy particular, de los pocos que se han dado en Colombia, sobre un trabajador de un banco quien, por su condición de especial protección, supone la utilización de medios tecnológicos en los lugares de trabajo. Aun así, la Corte dijo al respecto:

[...] la facultad de instalar mecanismos de vigilancia y control no puede ser ejercida de manera absoluta, aparejando una injerencia arbitraria en la esfera íntima de los trabajadores, y por tanto, en eventos en los cuales se encuentren en pugna el derecho a la intimidad del trabajador y el derecho del empleador a dirigir su actividad laboral, se deberá determinar las circunstancias específicas del caso en concreto, para ponderar los mismos en razón de la finalidad, proporcionalidad, necesidad e idoneidad de la medida, y por tanto determinar su razonabilidad, que deben encontrarse fundamentadas según el desarrollo inherente de la relación laboral. (Sentencia T-768, 2008)

Aunque hoy con mayor relevancia, la transformación en las modalidades de trabajo es una tendencia de desarrollo socioeconómico, empresarial y político, que ha hecho posible que el derecho laboral valore el papel que tienen las personas como sujetos que quieren y desean dignificar su existencia, de la mano del Estado social de derecho, con distintas modalidades de trabajo que reconocen la autonomía del trabajador, tales como el trabajo individual que es desarrollado desde el hogar gracias a los medios tecnológicos e informacionales: 
Tabla N.o 3

Conceptos de las modalidades de trabajos

\begin{tabular}{|l|l|}
\hline \multicolumn{1}{|c|}{ Modalidad } & \multicolumn{1}{c|}{ Concepto } \\
\hline Trabajo independiente & $\begin{array}{l}\text { Relación de subordinación } \\
\text { Recíprocas obligaciones, deberes y derechos } \\
\text { Regulado en el estatuto laboral }\end{array}$ \\
\hline $\begin{array}{l}\text { Trabajo dependiente } \\
\text { o autónomo }\end{array}$ & $\begin{array}{l}\text { Se realiza por cuenta propia - Inexistencia del vínculo de subordinación } \\
\text { Las utilidades fruto del trabajo en favor de sí mismo. } \\
\text { No título para ejercer la labor }\end{array}$ \\
\hline Trabajo material & $\begin{array}{l}\text { Actividad en la cual la fuerza física es predominante sobre el aspecto } \\
\text { intelectual }\end{array}$ \\
\hline Trabajo intelectual & $\begin{array}{l}\text { El aspecto intelectual o racional predomina sobre el físico o el aspecto } \\
\text { de la fuerza }\end{array}$ \\
\hline Trabajo permanente & Actividad laboral que se lleva a cabo en constante continuidad \\
\hline Trabajo transitorio & Actividad laboral de corta duración \\
\hline $\begin{array}{l}\text { Trabajo asociado o } \\
\text { cooperado }\end{array}$ & $\begin{array}{l}\text { Se desarrolla por un determinado grupo de personas asociadas que esta- } \\
\text { blecen sus propios estatutos de funcionamiento }\end{array}$ \\
\hline Trabajo informal & $\begin{array}{l}\text { Se realiza sin las formalidades establecidas por la ley, la mayoría de } \\
\text { las ocasiones se agrupan trabajadores independientes no profesionales, } \\
\text { pequeños empresarios y servicio doméstico }\end{array}$ \\
\hline
\end{tabular}

Elaboración propia, recoge la clasificación de Guerrero (1999).

Se destaca el aumento de modalidades de trabajo transitorio, que superan la concepción tradicional de la jornada de trabajo con horarios de 8 horas en una única empresa o entidad pública, con ocasión del surgimiento de las Tic. En la actualidad, los Estados están llamados a regular una modalidad de trabajo bimodal, que incluye el espacio de la oficina y el espacio en casa; aunado el tiempo que el trabajador emplea para desarrollar su labor fuera de la jornada laboral, el tratamiento de los mensajes de voz o escritos que pasan por los grupos de trabajo o en las redes sociales en horarios no laborales. Al interior de un hogar, se vulnera la tranquilidad de sus miembros cuando el trabajador deja de realizar sus labores de familia para responder un mensaje por whatsapp, justificado por la emergencia de los asuntos que así mismo son establecidos por este medio fuera de la jornada laboral por parte de su jefe, y que afectan sus condiciones de bienestar y dignidad humana (Guarín y Aldana, 2016). 


\section{Límites y desarrollo jurisprudencial}

La Corte Constitucional reconoce la Directiva 94/46/CE, por medio de la cual se regula el tratamiento de datos personales a nivel general (incluyendo el ámbito laboral), en el marco de los principios de calidad del dato y legitimación en el tratamiento del dato por parte de las empresas, y que garantiza el derecho a la libertad y el derecho a la intimidad de todas las personas como derechos fundamentales en un estado social de derecho: "la protección de las libertades y de los derechos fundamentales a las personas físicas y, en particular, del derecho a la intimidad, en lo que respecta al tratamiento de datos personales" (Sentencia C-748, 2011).

De manera particular, establece el límite de crear perfiles, con base en la información de las personas que circula en la web, para identificar los aspectos de su personalidad más sobresalientes en sus relaciones cotidianas:

1. Los Estados miembros reconocerán a las personas el derecho a no verse sometidas a una decisión con efectos jurídicos sobre ellas o que les afecte de manera significativa, que se base únicamente en un tratamiento automatizado de datos destinado a evaluar determinados aspectos de su personalidad, como su rendimiento laboral, crédito, fiabilidad, conducta, etc. (Directiva 94/46/CE, art.15)

De igual manera acoge la protección de los menores de edad en el tratamiento de datos personales, en virtud del interés superior del niño en los casos de "explotación laboral o económica y trabajos riesgosos":

(iii) Protección del niño frente a riesgos prohibidos. Se debe resguardar a los niños de todo tipo de abusos y arbitrariedades, y protegerlos frente a condiciones extremas que amenacen su desarrollo armónico, tales como el alcoholismo, la drogadicción, la prostitución, la violencia física o moral, la explotación económica o laboral, y en general, el irrespeto por la dignidad humana en todas sus formas. No en vano el artículo 44 de la Carta señala que los niños "serán protegidos contra toda forma de abandono, violencia física o moral, secuestro, venta, abuso sexual, explotación laboral o económica y trabajos riesgosos." Por su parte, el artículo 20 del Código de la Infancia y la Adolescencia establece el conjunto de riesgos graves para los niños que deben ser evitados [...]. (Corte Constitucional, Sentencia T-502, 2011, énfasis agregado) 
Otro limite, en la garantía de este derecho, es la falta de conocimiento del adecuado uso de la información de los datos personales, por parte de los operadores de la información a nivel empresarial; así como la falta de normas vinculantes y la ausencia de políticas de protección de la privacidad en el sistema online, lo cual no permite gestionar los riegos de manera prioritaria y evitar sanciones, ni garantizar un derecho fundamental de gran importancia, dado el impacto positivo pero también negativo que ha tenido la tecnología en las relaciones interpersonales y socioeconómicas en general (Sarmiento, Medina y Plazas, 2017).

Otro tema importante para tener presente es el "alcance del derecho a la intimidad frente a la divulgación de conversación virtual de grupo whatsapp, creado en el entorno laboral" (Sentencia T-574, 2017), estudiado con un enfoque según el espacio y el contexto de la privacidad.

Es decir, reconocer este derecho significaría que puede ser objeto de limitaciones, por parte del Estado, cuando estas se encuentren debidamente sustentadas. Para ello, debe existir autorización por parte del titular o una orden dictada por autoridad competente y en ejercicio de sus funciones, para permitir a los terceros conocer asuntos que por derecho son objeto de un correcto tratamiento de la información dentro del ámbito de protección. En otras palabras, el derecho a la intimidad puede ser: "susceptible de limitación por razones legítimas y debidamente justificadas constitucionalmente”. En ese sentido, este Tribunal ha señalado

[...] que uno de los aspectos centrales en la definición del alcance del derecho a la intimidad, consiste en determinar cuándo (i) una intromisión en la órbita que la persona o la familia se ha reservado para sí, (ii) una divulgación de hechos o datos privados o (iii) una restricción a la libertad de decidir, se encuentra justificada constitucionalmente. (Sentencia T-574, 2017)

\section{Conclusiones}

Si bien es cierto que existe una regulación sobre el tratamiento de datos personales de carácter general, por parte de la Ley 1581 de 2012, en el ámbito laboral existen limitantes respecto a la regulación del uso de las nuevas tecnologías en desarrollo de las relaciones laborales, tanto a nivel público como empresarial, que desconocen 
la garantía de los derechos fundamentales, tales como la privacidad, la intimidad personal dentro del núcleo familiar y el principio de la dignidad humana.

En referencia a los pronunciamientos de la Corte Constitucional, esta ha sido enfática en reconocer los derechos fundamentales que incorpora el modelo europeo de tratamiento de datos personales, y encuentra un reto importante en la adecuación de los estándares de tratamiento de datos personales de los estados iberoamericanos, en relación con la adecuada gestión de los riesgos y seguridad digital en el ámbito empresarial y con el uso de las nuevas tecnologías aplicables al ámbito laboral en casos específicos e innovadores, según el espacio y contexto de privacidad en la web.

Se requiere de la arquitectura de la privacidad por diseño y por defecto, de los códigos de conducta laboral, y de normas vinculantes a nivel empresarial, que minimicen los incidentes digitales y la vulneración de derechos fundamentales de los trabajadores, buscando el equilibrio de la libertad e iniciativa empresarial.

De alguna manera se reconoce el uso del correo electrónico y de algunas de sus limitantes, pues se contemplaba que este correo debería ser eficaz y no prestarse para situaciones de vulnerabilidad dentro de la estructuración de la empresa como tal. De esta manera, daba pie a ciertos abusos que a futuro conllevarían la creación de inconvenientes legales. Por esta razón, se construye un concepto diferente respecto al correo electrónico institucional, y lo vincula directamente a su principal función. Se trata de una herramienta de trabajo, a disposición de los trabajadores, en pro del desarrollo empresarial que tienen dentro de la empresa a la cual están afiliados, y no necesariamente sería adecuado incluir ciertos temas de carácter sindical dentro de las fuentes de estos correos electrónicos, de una u otra manera se violaría el derecho a la libre expresión y a la privacidad dentro del vínculo laboral para los trabajadores. Aunque esta modalidad de correo empresarial se debe asumir en todas las empresas, pues es absurdo pensar que la instalación de una moderna tecnología de la comunicación sea utilizada para otros fines de carácter no profesional, claro está que suponemos que cada empresa debe constituir un manual de manejo que se le dará a este correo institucional. Del mismo modo, asumimos que la finalidad exclusivamente radica como instrumento de trabajo y de comunicación entre subalternos en sus diferentes aéreas laborales.

Dentro de las obligaciones del empleador con el trabajador, podemos añadir el derecho de libertad sindical, que deben garantizar todas las empresas en Colombia. De esta manera, podemos iniciar la construcción de una herramienta de comunicación entre los sindicatos, so pena que pueda ser intervenida toda esta información a 
favor del empleador, respecto a cuestiones de índole laboral o penal que subsistan dentro del vínculo empresarial.

En palabras concretas, jurídicamente el sindicato cuenta con un respaldo para que puedan contar con un sistema de correo electrónico sindical y que este sea garantizado por el empleador, asumiendo de esta manera su parte en la creación y estructura que este amerita para su pleno funcionamiento, aparte de tener que contar con todas las normas de seguridad y con bases datos que soporten toda la información que allí se maneja.

En ciertos factores, insisto en que se debe realizar una diferenciación entre esos dos tipos de comunicación interna de las empresas, porque la finalidad del uno es muy diferente a la del otro. Por ejemplo, el empleador puede capacitar respecto al uso adecuado del correo institucional de la empresa, bajo estos factores de cumplimiento como lo son, justificando que, mediante la utilización del mismo, se está generando un aporte al medio ambiente y a la reutilización de toda la parte de papelería de la empresa; por ello, cuando todos los tramites, papeleos y documentos se manejan vía electrónica, esto contribuye al sostenimiento ecológico que la empresa maneja, pues hoy en día es un pilar fundamental en el posicionamiento de las mismas, a la vez que cumple cabalmente el estándar de productividad de la empresa.

Finalmente, el problema radica en que no existe, en nuestro ordenamiento jurídico laboral, una norma legal o convencional que se adapte a este nuevo inconveniente, originado por la realidad tecnológica que está afrontando el país con las llamadas Tic, y que obligará a que cada empresa se capacite y esté a la altura de estos nuevos mecanismos de carácter productivo, como lo decía antes. Lógicamente esta se considera una derivación del derecho de información sindical, integrado con carácter más genérico en el derecho fundamental a la libertad sindical. De esta manera, se debe estar preparados para asumir cientos de procesos laborales entre los trabajadores y los empleadores, y poder analizar más a fondo si, entre las causales de retiro de la actividad laboral que contempla nuestro Código Sustantivo del Trabajo, se consagra la violación del debido proceso, la libertad de expresión, la privacidad $\mathrm{y}$ todos aquellos derechos que son inherentes a los trabajadores.

\section{Referencias}

Barragán, D. (2016). La construcción de la mentalidad democrática como necesidad en el posconflicto. Revista Via Inveniendi et Iudicandi, 11(1), 37-57. 
Congreso de Colombia. (26 de diciembre de 1968). Ley 74 de 1968. Recuperada de https://www.mininterior.gov.co/sites/default/files/upload/SIIC/Jurisprudencia/antes1991/ley_74_de_1968.pdf

Congreso de Colombia. (17 de octubre de 2012). Ley Estatutaria de Protección de Datos Personales. [Ley 1581 de 2012]. DO: 48.587. Recuperado de http://wsp.presidencia. gov.co/Normativa/Leyes/Documents/LEY\%201581\%20DEL\%2017\%20DE\%20 OCTUBRE\%20DE\%202012.pdf

Constitución política de Colombia [Const.]. (1991). Recuperado de http://www.secretariasenado.gov.co/index.php/constitucion-politica

Corte Constitucional, Sentencia T-295, 2007.

Corte Constitucional, Sentencia T552, 1997.

Corte Constitucional, Sentencia T-718, 2005.

Corte Constitucional, Sentencia C-401, 2005.

Corte Constitucional, Sentencia T-124 de 1993.

Corte Constitucional, Sentencia C-107 de 2002.

Corte Constitucional, Sentencia T-768 de 2008.

Corte Constitucional, Sentencia C-748, 2011.

Corte Constitucional, Sentencia T-502, 2011.

Corte Constitucional, Sentencia T-574, 2017.

Forero, J. (2014). El valor superior de la Justicia en la Unión Europea. Especial referencia al Estado Constitucional Social y Democrático de Derecho Español. Revista Verba Iuris, 31, 91-114. Recuperado de https://revistas.unilibre.edu.co/index.php/verbaiuris/ article/view/59/53

Garzón, E. (2013). Globalización del derecho: fetichismo legal, el velo de los Derechos Humanos. Revista Verba Iuris, 30, 45-78

Guarín, E. A. y Aldana, J. (2016). Estado jurisdiccional y bien común. Revista Verba Iuris, 11(36), 13-26.

Guerrero, G. (1999). Teoría general del derecho laboral. Bogotá, Colombia: Leyer.

Organización Internacional del Trabajo [OIT]. (1997). Protección de los datos personales de los trabajadores. Repertorio de recomendaciones prácticas. 
Organización para la Cooperación y el Desarrollo Económico [ocde]. (2002). Directrices de la OCDE sobre protección de la privacidad y flujos transfronterizos de datos personales. Recuperado de https://www.oecd.org/sti/ieconomy/15590267.pdf

Parlamento Europeo y del Consejo. (2016). Reglamento europeo 679. Tratamiento de datos personales.

Raso, J. (2010). El impacto de las nuevas tecnologías en la privacidad e intimidad del trabajador. Revista Actualidad Laboral, 157, 10-15. Recuperado de http://legal.legis.com.co/ document?obra=rlaboral\&document=rlaboral_8149362f19fa4028e0430a0101514028

Raso, J. (2013). Nuevas tecnologías: conflictos entre el interés de la empresa y la vida privada del trabajador. Revista Internacional y Comparada de Relaciones Laborales y Derecho del Empleo, 2(1), 1-16. Recuperado de http://ejcls.adapt.it/index.php/rlde_adapt/article/ view/181

Remolina Angarita, N. (2013). Tratamiento de datos personales en el contexto laboral. Revista Actualidad Laboral, 175, 19-24. Recuperado de http://legal.legis.com.co/docu ment?obra=rlaboral\&document=rlaboral_d6cac6ef1ad80028e0430a0101510028

Roig, A. (2010). Derechos fundamentales y tecnologias de la información y de las comunicaciones (TICs). Barcelona, España: J. M. Bosch Editor.

Sáenz, I. (2015). El derecho a la intimidad personal en el ámbito laboral. (Tesis de grado, Universidad de La Rioja). Recuperado de http://biblioteca.unirioja.es/tfe_e/TFE000974.pdf

Sarmiento, D., Medina, S. y Plazas, R. (2017). Sobre la responsabilidad y su relación con el daño y los perjuicios. Revista Via inveniendi et Iudicandi, 12(2), 101-115.

Segura, D. (2015). El derecho a la intimidad del trabajador como restricción al poder subordinante del empleador: el incipiente desarrollo en Colombia frente al derecho comparado. Revista de Derecho Público, 34. Recuperado de https://derechopublico.uniandes.edu.co/ components/com_revista/archivos/derechopub/pub482.pdf

Tribunal Constitucional Español. (2000). Sentencia STC 292/2000.

Tribunal Uruguayo de Apelaciones de Trabajo. (2004) Sentencia 312/2004.

Tribunal Uruguayo de Apelaciones de Trabajo. (2007). Sentencia 103/2007. 